\title{
Effect of Scarpa's fascia Preservation during Abdominoplasty on post-operative seroma formation in overweight patients
}

G.I.Elhabaa, M.A.Mansour, M.O.Mohammed, M.T.Younes and A.M.Abdelmofeed

General \& Plastic Surgery, Dept.,Faculty of Medicine, Benha Univ., Benha, Egypt

E-Mail:Mohammedosama@gmail.com

\begin{abstract}
Presentation: Weight misfortune may prompt stomach skin repetition which causes distorting shape for the mid-region and flanks, so as a rule abdominoplasty is required. Point of study: A forthcoming investigation of 35 patients was intended to assess seroma arrangement in abdominoplasty fold height on more shallow plane with scarpa belt safeguarding. Results:The seroma arrangement either early or late were more in old style strategy and there was no significant contrast in injury contamination and dehiscence between the two strategies while Keloid development showed more possibility in traditional procedure. Conversation: There were two particular zones of lymph seepage that incorporated the epigastric zone channels to the axilla and the hypogastric territory channels to the inguinal region. The associations between the profound fat compartment and the inguinal region were kept up after scarpa belt safeguarding. Some blood supply and lymphatic waste could be held contrasted with the extraction of scarpa belt. End: Based on this examination scarpa's belt safeguarding abdominoplasty is suggested, for being more dependable, better scar shape and more acceptable for the patients.
\end{abstract}

Keywords: Scarpa, preservation, Abdominoplasty, seroma, overweight.

\section{Introduction}

Abdominoplasty and related body forming systems have kept on expanding in number both in stylish and in post-bariatric medical procedure patients. The American Society for Esthetic Plastic Surgery Cosmetic Surgery National Data Bank detailed that the quantity of abdominoplasty systems had expanded in excess of $300 \%$ over the previous decade. [1] Postoperative seroma development stays perhaps the most incessant intricacies following an abdominoplasty technique [2].

Seroma is characterized as a generous subcutaneous stomach divider liquid assortment after channel expulsion with the liquid requiring goal in any event once. [3] Seromas may require various percutaneous goals, and some may in the end bring about pseudo-growths. Indeed, even a subsequent activity might be expected to control the movement to the ongoing state. [4] The pace of seroma development following abdominoplasty has been accounted for high and is thusly connected with longer medical clinic stays and more incessant specialist visits after release [5].

Abdominoplasty seroma liquid takes after an incendiary exudate. Absolute protein, lactate dehydrogenase, and cholesterol levels are higher in seroma than in lymphatic liquid. Neutrophil includes are likewise higher than in blood or lymphatic liquid. Seroma liquid contains fundamentally more significant levels of the favorable to incendiary cytokines tumor corruption factor- $\alpha$ and interleukin- 6 flagging more tissue harm and a more prominent fiery reaction. [6] Partial subfascial abdominoplasty was first recommended by Le Louarn to diminish the pace of seroma development following this strategy [7].

Scarpa belt is typically disregarded in the old style portrayals of the abdominoplasty careful strategy, yet it has been proposed that it might have a significant job in this kind of a medical procedure by diminishing quite possibly the most incessant difficulties, seroma [8].
Costa-Ferreira et al. hypothesize that parallel safeguarding of the Scarpa sash protects profound lymphatic seepage channels and along these lines diminishes the danger of liquid aggregation. [9] The helpful impact of utilizing a more shallow plane of analyzation on the seroma rate has been completely affirmed alongside other important benefits: lower channel volume, prior channel expulsion, avoidance of long drainers, more limited clinic stay, and lower hematoma and contamination rates [3].

Stomach fold ought to be raised on two diverse careful planes rather than the single plane utilized on an old style abdominoplasty: in the supra umbilical locale a premuscular plane, indistinguishable from the one utilized in a traditional full abdominoplasty and in the infra umbilical area a more shallow plane of analyzation at Scarpa sash level. The primary objective of this change was to bring down the seroma rate through lymphatic protection. [8]

The investigation will incorporate 35 patients with abundance stomach skin, fat tissue and foremost stomach divider muscle laxity for full abdominoplasty and umbilicus interpretation.

\section{Patients \& methods}

2.1. Patients will be divided into 2 groups:

- Group A: 20 Patients will undergo classic abdominoplasty withumbilicus transposition

- Group B: 15 patients will undergo abdominoplasty with umbilicus transposition with scarpa fascia preservation.

The study will be conducted in Banha university hospital duringperiod from October 2019 to march 2020.

\subsection{Exclusion criteria:}

- Chronic uncontrolled diseases: diabetes, hypertension, Ischemic heart disease.

- Patients with body mass index more than 40 and less than 25 Bariatric patients without weight stabilization for 6 months at least. 
- Previous abdominal operations.

- Ventral hernias.

\subsection{Preoperative preparation:}

All patients will undergo preoperative evaluation in the form of complete history taking, physical examination (general/local), complete laboratory investigations, photo documentation, preoperative marking and consent.

\subsection{Ethics:}

Written formal consent for including in the study, and photographingaccording to local ethical committee of Banha Faculty of Medicine.

\subsection{Techniques}

Operation done under general anesthesia. In group A, the abdominal flap will be dissected in a premuscular plane as traditionally described, to the level of the subcostal margin. In group B, the abdominal flap will be dissected in two different planes: pre-Scarpa fascia in the lower abdomen and premuscular in the epigastric region and infra-umbilical midline.

\section{Results}

From October 2019 to March 2020 a total of 35 patients underwent abdominoplasty operation at Banha university hospital and all operations were done by the same surgical team, 20 were done by classic technique and 15 were done by scarpa's fascia preservation abdominoplastyoperation.

\subsection{Demographic data}

The patients were between 21 and 46 years old (mean 32.2 \pm 6.21 ), All patients were females, all patients had previous deliveries 16 by caesarean section (CS) and 4 by normal labour, all patients were on post- operative antibiotics and analgesics and were advised to start walking and minimal activity after 12 hours postoperative and were advised to avoid heavy objects lifting for 6 months post operatively. The detailed demographic data is in Table (1).

Table (1) Demographic data.

\begin{tabular}{llccc}
\hline & & Classic technique (20) & scarpa's fasciapreservation (15) & p-value $^{*}$ \\
\hline Age & & $33.70 \pm 7.83$ & $32.73 \pm 9.93$ & 0.373 \\
Delivery & Vaginal & $3(15 \%)$ & $1(6.67 \%)$ & 0.688 \\
& CS & $17(85 \%)$ & $14(93.33 \%)$ & 0.235 \\
BMI & & $38.28 \pm 0.37$ & $38.64 \pm 1.25$ & 0.684 \\
\hline
\end{tabular}

*independent t-test, significant if $<0.05$

\subsection{Intraoperative data}

Regarding intraoperative data the mean operative time was $186 \pm 12.24$ with significant difference regarding both operative time and blood loss ( $\mathrm{p}$-value $<0.05)$.

Table (2) Intraoperative data.

\begin{tabular}{lccc}
\hline & Classic technique (20) & scarpa's fasciapreservation (15) & p-value* $^{*}$ \\
\hline Operative time(min) & $184 \pm 17.82$ & $178 \pm 10.93$ & 0.032 \\
Blood loss (cm) & $300 \pm 9.35$ & $224 \pm 8.69$ & 0.018 \\
\hline
\end{tabular}

*independent t-test, significant if $<0.05$

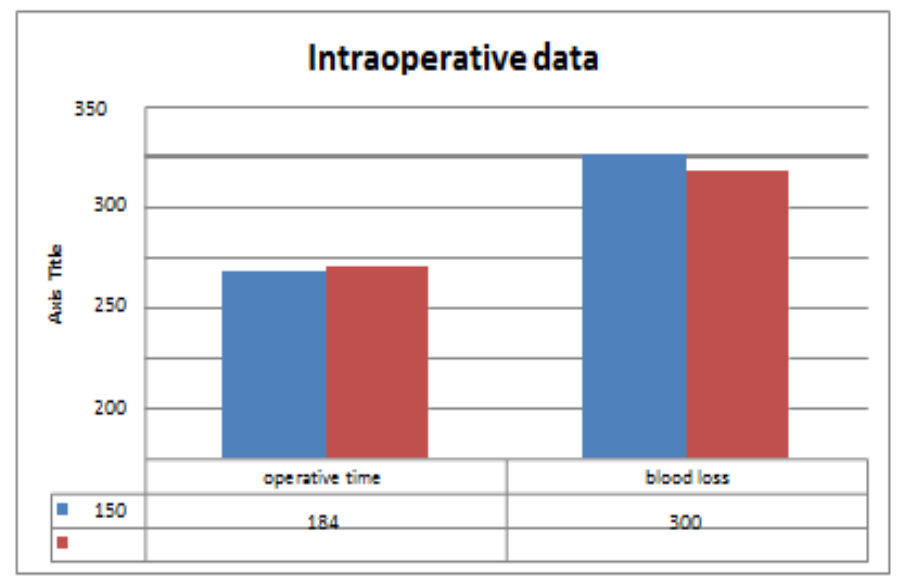

Fig. (1) Intraoperative data. 


\subsection{Postoperative data}

Early postoperative data

Hospital stay

Regarding the hospital stay, there was no significant difference ( $\mathrm{p}$ - value $>0.05$ ) between classic group (mean= $2.48 \pm 0.87$ ) and scarpa's fascia preservation group (mean= 2.27 \pm 0.63$)$

Table (3) Hospital stay.

\begin{tabular}{lccc}
\hline & Classic technique (20) & scarpa's fascia preservation (15) & p-value* $^{*}$ \\
\hline Hospital stay(days) & $2.48 \pm 0.87$ & $2.27 \pm 0.63$ & 0.478 \\
\hline
\end{tabular}

\section{Drain output \& removal}

Drains were removed after 7 to 10 days in all cases with no significant difference $(\mathrm{p}$-value $=0.212)$ between scarpa's fascia preservation group $(8 \pm 1.46)$ and classic group (9.6 \pm 1.53$)$. While drain output mean was

Table (4): Drain output \& removal.

\begin{tabular}{lccc}
\hline & Classic technique (20) & scarpa's fascia preservation (15) & p-value* \\
\hline Drain output (first week) & $200.75 \pm 52.27$ & $141.00 \pm 29.65$ & 0.027 \\
Drain removal (days) & $9.6 \pm 1.53$ & $8 \pm 1.46$ & 0.212 \\
\hline
\end{tabular}

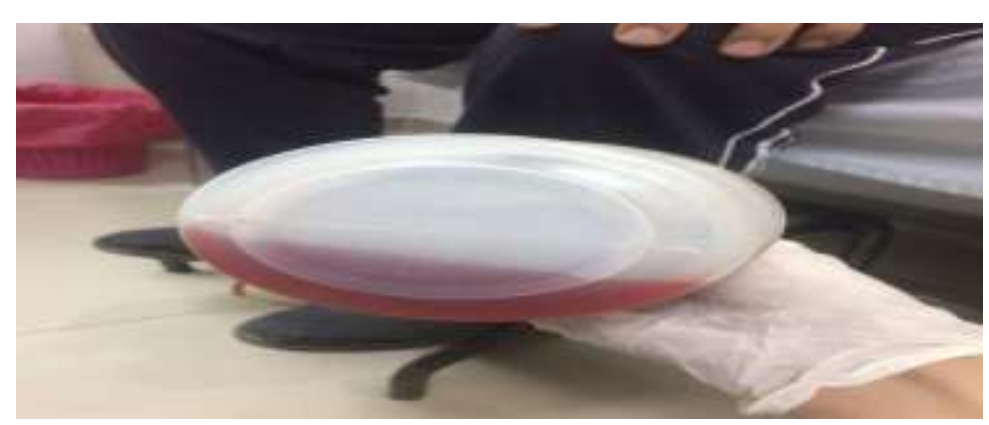

Fig (2): Drain showing serosangious collection in day 7 postoperative

\section{Late postoperative}

\section{Patient satisfaction}

In our study there was a significant difference ( $p$-value< 0.05 ) regarding the average SAPS score for all patients had classic abdominoplasty (21.3 \pm 2.05$)$, and for patients who had scarpa's fascia preservation (26.13).

Table (5) Patient satisfaction.

\begin{tabular}{lccc}
\hline & Classic technique (20) & scarpa's fasciapreservation (15) & p-value* \\
\hline SAPS & $21.3 \pm 2.05$ & $26.13 \pm 1.33$ & 0.013 \\
\hline
\end{tabular}

*independent t-test, significant if $<0.05$

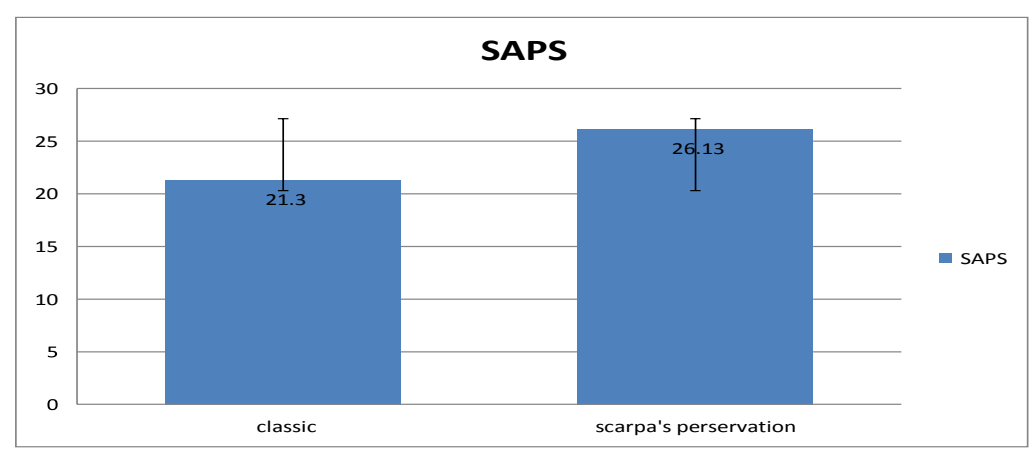

Fig. (3) Patient satisfaction 

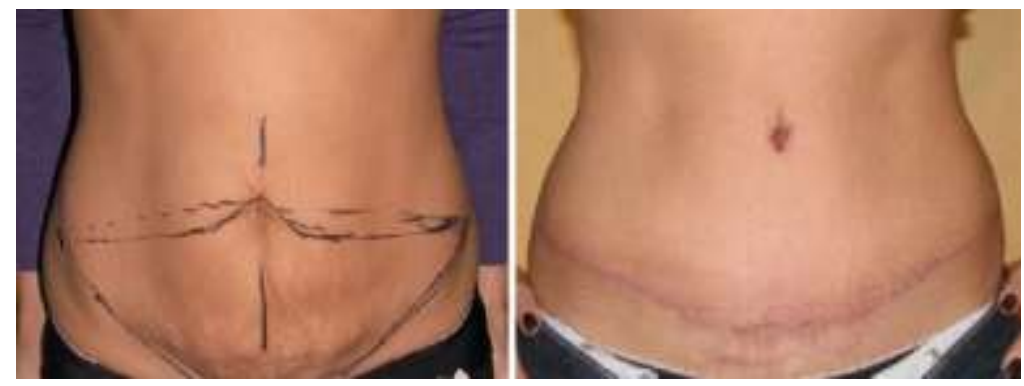

Fig. (4) A 39-year-old patient with $79 \mathrm{~kg}$ of weight loss who underwent total abdominal liposuction and scarpa's fascia preservation abdominoplasty through a low transverse incision. Above left: preoperative anterior view. Above right: postoperative anterior view.

Seroma formation either early Seroma (within the first month) orlate Seroma (after the first month):

Second week

Seroma within the second week post-operative were found in $100 \%$ of the patients in the study with a range of $20 \mathrm{cc}$ to $200 \mathrm{cc}$ (mean 69.86 \pm 43.47 ) of serosangious fluid during the second week postoperative with a significant difference ( $p$-value $<0.05)$ between both classic $(92.5 \pm 44.59)$ and scarpa's fascia preservation (39.67 \pm 13.56$)$.

Table (7) Seroma collection (second week).

\begin{tabular}{lccc}
\hline & Classic technique (20) & scarpa's fasciapreservation (15) & p-value* \\
\hline Seroma collection(second week) & $92.5 \pm 44.59$ & $39.67 \pm 13.56$ & 0.034 \\
& $(100 \%)$ & $(100 \%)$ & \\
\hline
\end{tabular}

*independent t-test, significant if $<0.05$

\section{Third week}

Seroma within the third week post-operative were found in $100 \%$ of the patients in classic group
(29.75 \pm 12.82$)$, while it presents only in $40 \%$ of Scarpa's fascia group $(7.67 \pm 7.04)$ with a significant difference (p-value $<0.00)$.

Table (8) Seroma collection (Third week).

\begin{tabular}{lccc}
\hline & Classic technique (20) & scarpa's fasciapreservation (15) & p-value* $^{*}$ \\
\hline Seroma collection(third week) & $29.75 \pm 12.82$ & $7.67 \pm 7.04$ & 0.012 \\
& $(100 \%)$ & $(40 \%)$ & \\
\hline
\end{tabular}

*independent t-test, significant if $<0.05$

\section{Fourth week}

Seroma within the fourth week post-operative were found in $40 \%$ of the patients in classic group

(9.5 \pm 8.16$)$, while it does not present in Scarpa's fascia group with a significant difference ( $p$-value $<0.05)$ with no further seroma was noticed after that.

Table (9): Seroma collection (Fourth week)

\begin{tabular}{lccc}
\hline & Classic technique (20) & scarpa's fasciapreservation (15) $^{\text {p-value* }}$ \\
\hline Seroma collection(fourth week) & $9.5 \pm 8.16$ & 0 & 0.001 \\
& $(40 \%)$ & & \\
\hline
\end{tabular}

*independent t-test, significant if $<0.05$

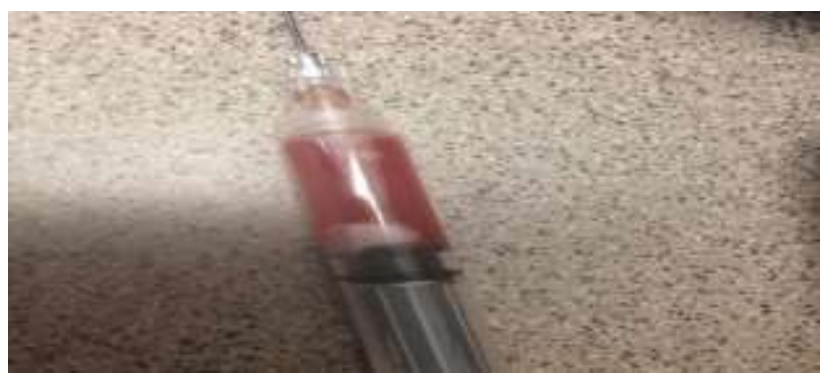

Fig. (5) Seroma collected in day 21 post-operative in classic abdominoplasty case. 


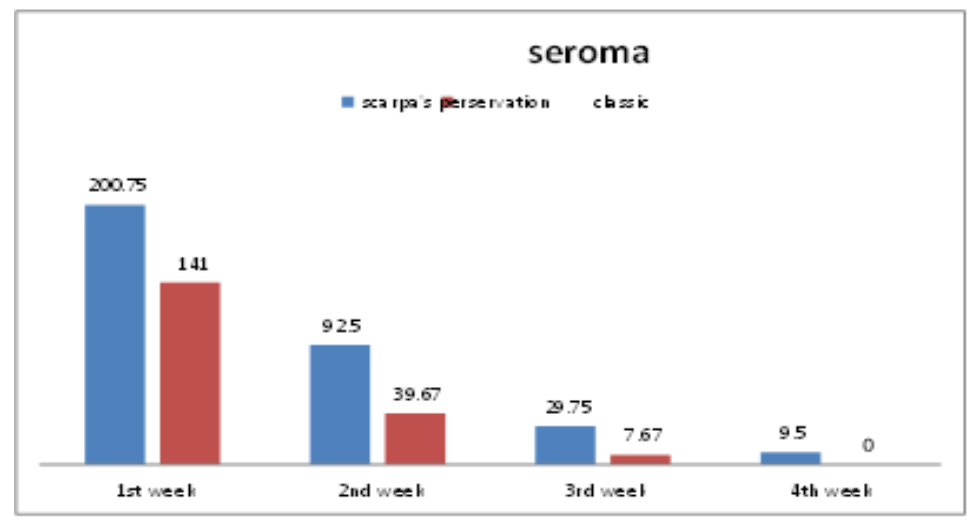

Fig. (6) Seroma collection.

Postoperative pain

The VAS showed a Signiant low value $(\mathrm{p}$-value $<0.05)$ for scarpa's fascia preservation group $($ mean $=5.83 \pm 3.57)$.

Table (10) VAS (visual analogue score).

\begin{tabular}{lccc}
\hline & Classic technique (20) & scarpa's fascia preservation (15) & p-value* \\
\hline VAS (visual analogue score) & $8.23 \pm 2.24$ & $5.83 \pm 3.57$ & 0.032 \\
\hline
\end{tabular}

*independent t-test, significant if $<0.05$

\section{Aesthetic outcomes}

The Likert scale showed a significant difference regarding the aesthetic outcome (p-value <0.05), with an overall upper percent of the very satisfied patient in scarpa's fascia preservation group.

Table (11) Aesthetic outcomes.

\begin{tabular}{|c|c|c|c|c|c|c|c|c|c|}
\hline \multirow[t]{2}{*}{ Likert scale } & \multicolumn{4}{|c|}{ Classic technique (20) } & \multicolumn{4}{|c|}{ Scarpa's fascia preservation (15) } & \multirow[b]{2}{*}{ p-value } \\
\hline & $\begin{array}{c}\text { Very } \\
\text { satisfied }\end{array}$ & satisfied & Unsatisfied & $\begin{array}{c}\text { Very } \\
\text { unsatisfied }\end{array}$ & $\begin{array}{c}\text { Very } \\
\text { satisfied }\end{array}$ & satisfied & Unsatisfied & $\begin{array}{c}\text { Very } \\
\text { unsatisfied }\end{array}$ & \\
\hline Contour & $\begin{array}{c}3 \\
(15) \%\end{array}$ & $\begin{array}{c}8 \\
(40 \%)\end{array}$ & $\begin{array}{c}6 \\
(30 \%)\end{array}$ & $\begin{array}{c}3 \\
(15) \%\end{array}$ & $\begin{array}{c}6 \\
(40 \%)\end{array}$ & $\begin{array}{c}5 \\
(33.33 \%)\end{array}$ & $\begin{array}{c}3 \\
(20 \%)\end{array}$ & $\begin{array}{c}1 \\
(6.67 \%)\end{array}$ & 0.014 \\
\hline Irregularties & $\begin{array}{c}4 \\
(20 \%)\end{array}$ & $\begin{array}{c}10 \\
(50 \%)\end{array}$ & $\begin{array}{c}4 \\
(20 \%)\end{array}$ & $\begin{array}{c}2 \\
(10 \%)\end{array}$ & $\begin{array}{c}7 \\
(46.67 \%)\end{array}$ & $\begin{array}{c}5 \\
(33.33 \%)\end{array}$ & $\begin{array}{c}2 \\
(13.33 \%)\end{array}$ & $\begin{array}{c}1 \\
(6.67 \%)\end{array}$ & 0.028 \\
\hline Scars & $\begin{array}{c}2 \\
(10 \%)\end{array}$ & $\begin{array}{c}7 \\
(35 \%)\end{array}$ & $\begin{array}{c}6 \\
(30 \%)\end{array}$ & $\begin{array}{c}5 \\
(25 \%)\end{array}$ & $\begin{array}{c}4 \\
(26.67 \%)\end{array}$ & $\begin{array}{c}8 \\
(53.33 \%)\end{array}$ & $\begin{array}{c}2 \\
(13.33 \%)\end{array}$ & $\begin{array}{c}1 \\
(6.67 \%)\end{array}$ & 0.019 \\
\hline Symmetry & $\begin{array}{c}7 \\
(35 \%) \\
\end{array}$ & $\begin{array}{c}8 \\
(40 \%) \\
\end{array}$ & $\begin{array}{c}4 \\
(20 \%) \\
\end{array}$ & $\begin{array}{c}1 \\
(5 \%)\end{array}$ & $\begin{array}{c}6 \\
(40 \%) \\
\end{array}$ & $\begin{array}{c}6 \\
(40 \%) \\
\end{array}$ & $\begin{array}{c}3 \\
(20 \%) \\
\end{array}$ & 0 & 0.011 \\
\hline
\end{tabular}

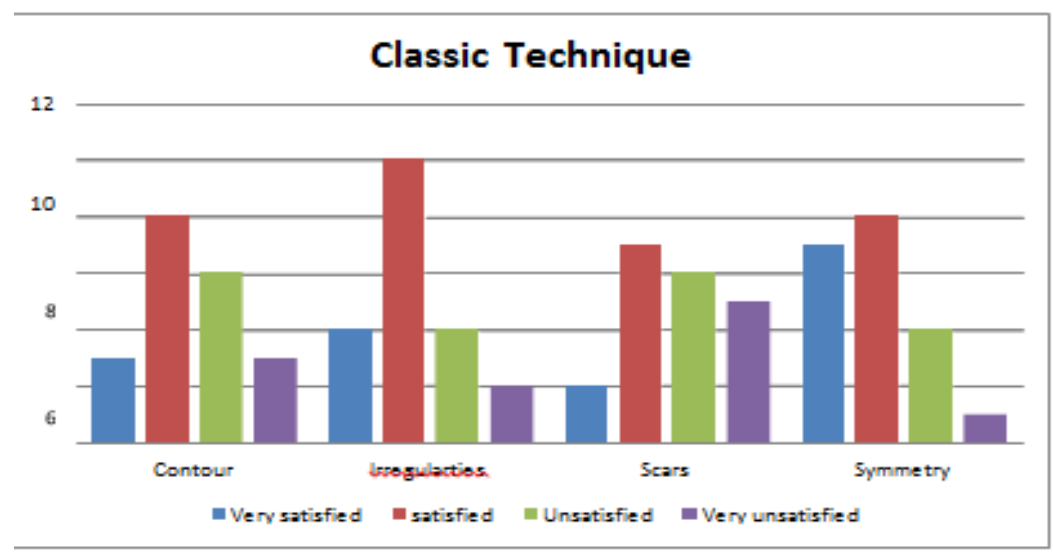

Fig. (7) Classic technique. 


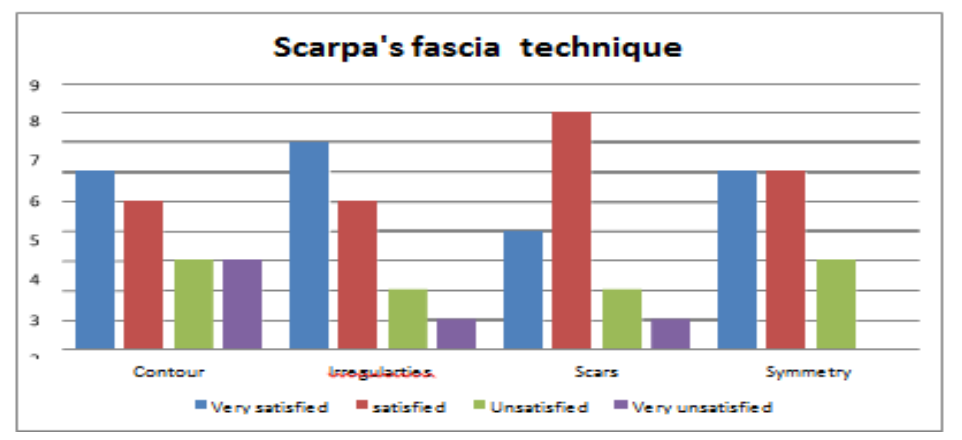

Fig. (8) Scarpa's fascia preservation.

\section{Wound infection and dehiscence:}

In classic abdominoplasty cases, three cases only complained of wound infection and one case in scarpa's preservation group. The infection was in distal part of the flap slightly to the right of the midline that appeared at day 15 postoperative Fig. (7), swab from the wound was taken and culture was done and found streptococcus infection that was sensitive to Quinolones. so Quinolones antibiotic was taken for 10 days duration and the infection was resolved, while wound dehiscence (one case in classic group) was dermal and was treated by secondary sutures operation at day 27 postoperative Fig.(8).There was no significant difference between both groups ( $\mathrm{p}$ value $<0.05$ ).

\section{Keloid and hypertrophic scar formation:} In classic abdominoplasty:

Hypertrophic scar was formed in three case (15\%), both females one 41years old and the other 39 years old, the problem was noticed in week 12 and 14 postoperative at suture line and around umbilicus and silicon gelwas advised to reduce scar effect Fig. (11).

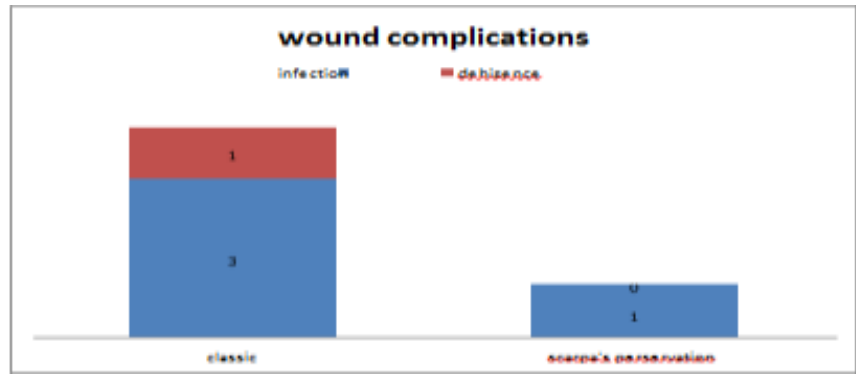

Fig. (9) Wound complications.

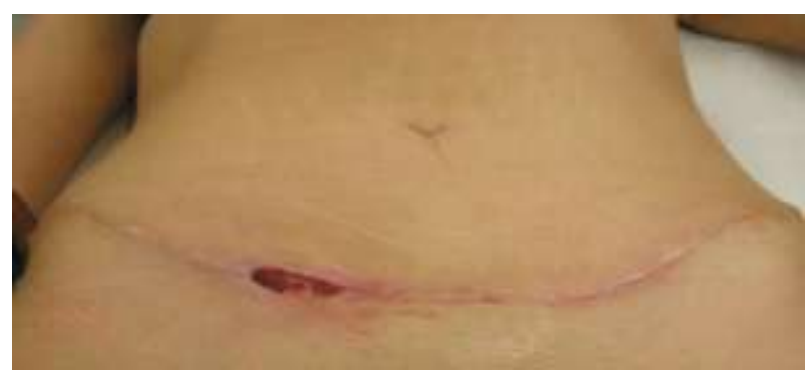

Fig. (10) Showing wound dehiscence at the wound of abdominoplasty at day 15 postoperative.

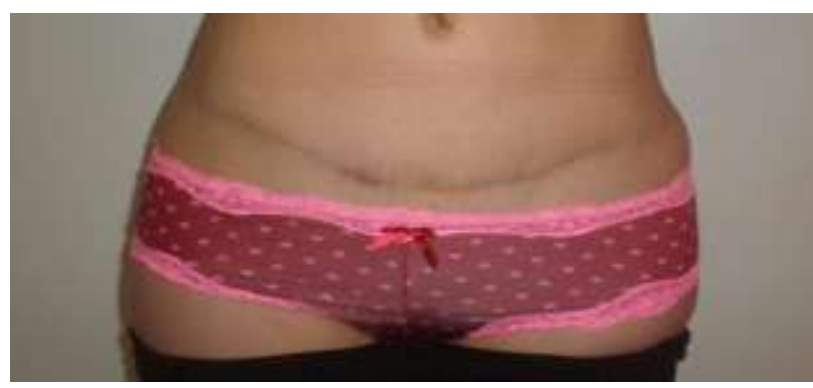

Fig. (11) Showing the wound after complete healing at month 2 after secondarysuture operatin and month 3 after abdominoplasty. 


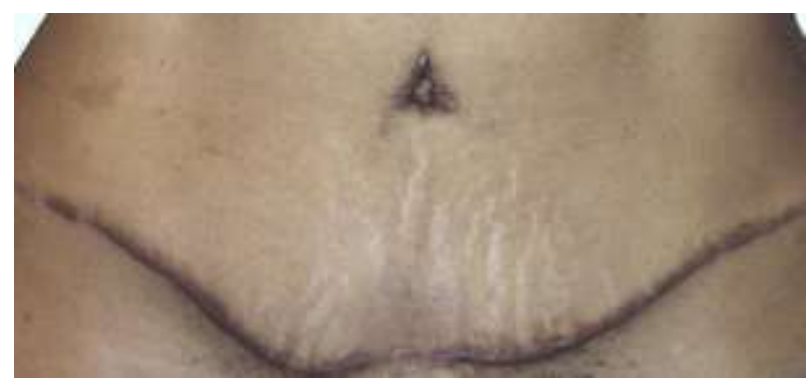

Fig. (12) Showing hypertrophic scar after classic abdominoplasty week 11 postoperative.

In scarpa's fascia preservation group, hypertrophic scar was formed in 1 case $(6 \%)$, was a female 38 years old, it was noticed in week 11 postoperative at the suture line and around umbilicus and silicone sheet was advised Fig. (12)

\section{Discussion}

Stoutness is viewed as quite possibly the most widely recognized medical issues in 21 th century, Obesity has a few negative consequences for the mental status, and the seriousness of mental issues connects with the level of corpulence. An examination distributed in "The New England Journal of medication 2017" has uncovered that in excess of 2 billion grown-ups and kids all throughout the planet are either overweight or corpulent. Heftiness is characterized as a BMI of $30 \mathrm{~kg} / \mathrm{m} 2$ or more. [1]

Around $20 \%$ of stout individuals are very big boned, characterized as a BMI of at any rate $40 \mathrm{~kg} / \mathrm{m} 2$ or a BMI of at any rate $35 \mathrm{~kg} / \mathrm{m} 2$ within the sight of high-hazard comorbid conditions like hypertension, coronary course infection, cerebral ischemia, fringe venous inadequacy, thrombophlebitis, obstructive rest apnea, corpulence hypoventilation disorder, diabetes mellitus, hyperlipidemia, and back circle herniation or osteoarthritis of weight bearing regions, among others. Egypt is leading the pack. The examination tracked down that $35 \%$ of Egyptian grown-ups experience the ill effects of corpulence. [28]

Abdominoplasty is perhaps the most widely recognized plastic methodology in post bariatric weight reduction. In certain patients, fast weight reduction and skin changes lead to repetition of the skin of midsection and flanks which require abdominoplasty system to take care of this issue, particularly in females who had went through cesarean area and have feeble front stomach divider muscles. [8]

Our investigation recommended that contrasted with the extraction of scarpa sash, scarpa belt safeguarding showed a significant capacity to diminish seroma time until channel evacuation, channel yield, and emergency clinic stay, yet had no impact on hematoma/dying, disease, and stitch burst in patients with abdominoplasty. [29[

The subcutaneous tissue of the stomach divider comprises of two particular fat compartments, shallow and profound, which are isolated by the scarpa belt . Conservation of the scarpa sash was joined by safeguarding of the profound fat compartment alongside its connective tissue, lymphatic vessels, supply routes, and veins [25]. There were two unmistakable regions of lymph seepage that incorporated the epigastric territory channels to the axilla and the hypogastric region channels to the inguinal region. The associations between the profound fat compartment and the inguinal region were kept up after scarpa sash safeguarding. Some blood supply and lymphatic waste could be held contrasted with the extraction of scarpa sash [4].

Le Louarn [7] speculated that keeping up the profound fat compartment regarded the life structures of the mid-region and kept a bed of all around vascularized tissue with its local lymphatic waste safeguarded which supported recuperating and stayed away from seroma arrangement. [7] Friedman [30] confirmed that up to $17 \%$ of the lymphatic seepage of the stomach divider is kept up if the analyzation is performed above Scarpa belt. Another conceivable component has been proposed dependent on a "stickier" interface between the upper fold and Scarpa sash rather than the profound belt in the traditional strategy. This cement model is basically a consequence of the adaptable idea of the profound fat compartment.[30]

The last may disclose a higher protection from the shearing powers between tissue planes and consequently a quicker recuperating and adherence measures. The two components, physiological and mechanical, might be included. Abdominoplasty is related with a higher complexity rate than other body form systems and the most successive is seroma, with a detailed rate from 5 to half. [31]

The pathogenesis of post abdominoplasty seromas stays tricky, and a few clarifications have been recommended. Rise of the huge skin fold brings about serous liquid assortment following the fiery boost of injury. Fold height and excess skin resection could harm lymphatic vessels and lead to an undermined condition of lymphatic seepage after the activity. Moreover, any dead space may prompt the development of intense liquid assortments [3].

Scarpa belt conservation on the infraumblical region could secure a few constructions and physiology of the stomach divider, and hypothetically, it could diminish seeping (because of the protection of the substandard puncturing vessels), advance great adherence between the fold and the profound layers, and result in less liquid assortment and seroma development because of 
safeguarding of profound lymphatic vessels as affirmed by some clinical examinations [32].

Furthermore, the profound fat compartment was saved during scarpa belt conservation which may bring about a more regrettable stomach form when contrasted and customary abdominoplasty. Notwithstanding, patients with scarpa belt safeguarding got similar fulfillment, last stomach shape, and tasteful outcomes when contrasted with those without conservation of the scarpa sash. This may be clarified by the way that the profound fat compartment has an insignificant commitment to the complete stomach thickness [33]. In our examination we looked at among Classic and scarpa's sash protection abdominoplasty strategies as indicated by persistent fulfillment score by [34] called Short Assessment of Patient fulfillment (SAPS). In exemplary strategy the SAPS was mean was 21.30; Most of unacceptable focuses were a direct result of repetitive flanks contrasted and focal mid-region, height of the scar along the side which can be showed up while the patient is wearing her clothing, and Keloid development which was more apparent. While in Scarpa's sash protection the mean SAPS was 26.13.

Perhaps the most acknowledged techniques for seroma anticipation after a full abdominoplasty is the utilization of pull channels. This was affirmed by Matarasso's overview of 497 plastic specialists who had performed 11,016 abdominoplasties: $98 \%$ of the specialists utilized attractions channels and the normal time until channel evacuation was 8 days. (35) Other creators likewise gave significant stretches of time channels (a day and a half), in two planned examinations in non-bariatric patients. Protecting Scarpa belt diminished these qualities by 3 days $(38,39)$. Tooth revealed a comparative reduction(5). Channels are typically eliminated when there is under $30 \mathrm{ml}$ of suction gathered in each channel over a 24 hour time frame yet this rules might be distinctive among specialists [40].

Some normal inadmissible focuses in the two methods were about seroma arrangement which released from the injury. All patients in the investigation went through the activity in a similar emergency clinic and by a similar careful group, they all had a similar preemployable planning thinking about labs and imaging contemplates, they all had a similar post-usable mind and follow up thinking about drugs, wound consideration and dressing, undergarment application and follow up periods.

In fact, the exemplary strategy for abdominoplasty is simpler and more utilized among specialists all throughout the planet; exemplary abdominoplasty method is done in practically $78 \%$ among all abdominoplasty cases in USA followed by circumferential abdominoplasty about $11 \%$ and High horizontal pressure abdominoplasty about $6 \%$ among abdominoplasty cases in USA [3].

There was a major distinction in seroma arrangement between the two strategies of abdominoplasty; Scarpa's sash conservation strategy shows a critical lower measure of serous liquid during first, second and third weeks with no seroma development in fourth week. Altogether patients seroma was mitigated by pressure inside the space of weeks post-usable. Koller [41] revealed comparable discoveries in regards to deplete volume decrease with double plane abdominoplasty.[41]

Wound dehiscence show no distinction in any of abdominoplasty methods and it could be expected to over analyzation of the folds horizontally or deformity in blood supply to the folds because of past pre-employable constant clinical issues in the patient as Diabetes or atherosclerosis or delayed tight pressure on the midsection postoperative prompting distal ischemia to the folds and wound dehiscence [33].

In our examination, Keloid and hypertrophic scar showed more tasteful issues to the patients in exemplary gathering, so the patients in this gathering were more worried about scar shape. In view of our current investigation, we urge specialists to successfully do scarpa's sash abdominoplasty, in light of low frequency of postoperative horribleness.

In light of this examination scarpa's sash protection abdominoplasty is suggested, for being more solid, better scar shape and more agreeable for the patients.

\section{Conclusion}

Weight reduction may prompt stomach skin excess which causes distorting shape for the mid-region and flanks, so by and large abdominoplasty is required.

Each abdominoplasty method has its benefits and drawback particularly in patients who experience the ill effects of many skin and shape changes in a quick manner.

Among all abdominoplasty strategies exemplary and scarpa's belt conservation strategies were applied in this examination and result, intricacies and patient fulfillment were observed to assess and find out about the best method to be done in such patients.

The seroma arrangement either early or late were more in old style method and there was no significant distinction in injury disease and dehiscence between the two strategies while Keloid development showed more possibility in traditional procedure.

In light of this examination scarpa's belt safeguarding abdominoplasty is suggested, for being more dependable, better scar shape and more good for the patients.

\section{References}

[1] B.Ardehali, F.Fiorentino, A meta-analysis of the effects of abdominoplasty modifications on the incidence of postoperative seroma. Aesthetic surgery journal;VOL.37(10),PP.1136-43,2017.

[2] M.E. Bercial, M.S. Neto, J.A. Calil, L.A. Rossetto, L.M .Ferreira,Suction drains, quilting sutures, and fibrin sealant in the prevention of seroma formation in abdominoplasty: which is the best strategy? Aesthetic Plastic Surgery;VOL.36(2),PP.3703,2012.

[3] A. Costa-Ferreira, M. Rebelo, A. Silva, L.O. Vásconez, J.Amarante, Scarpa fascia preservation during abdominoplasty: randomized clinical study of 
efficacy and safety. Plastic and Reconstructive Surgery;VOL.131(3),PP.644-51,2013.

[4] M. Di Martino, F.X. Nahas, A.K. Kimura, N. Sallum, L.M. Ferreira, Natural evolution of seroma in abdominoplasty. Plastic and Reconstructive Surgery;VOL.135(4),PP.691-8,2015.

[5] R.C. Fang, S.J. Lin, T.A. Mustoe, Abdominoplasty flap elevation in a more superficial plane: decreasing the need for drains. Plastic and reconstructive surgery;VOL.125(2),PP.677-82,2010.

[6] K.C. Neaman, S.D. Armstrong, M.E. Baca, M. Albert, D.L. Vander Woude, J.D .Renucci, Outcomes of traditional cosmetic abdominoplasty in a community setting: a retrospective analysis of 1008 patients. Plastic and Reconstructive Surgery;VOL.131(3),PP.403-10,2013.

[7] C. Le Louarn ,Partial subfascial abdominoplasty. Aesthetic plastic surgery;VOL.20(2),PP.123-7,1996.

[8] S.S. Tourani, G.I. Taylor, M.W. Ashton, Scarpa fascia preservation in abdominoplasty: does it preserve the lymphatics? Plastic and Reconstructive Surgery;VOL.136(2),PP.258-62,2015.

[9] G. Hawthorne, J .Sansoni, L .Hayes, N. Marosszeky, E.Sansoni, Measuring patient satisfaction with health care treatment using the Short Assessment of Patient Satisfaction measure delivered superior and robust satisfaction estimates. Journal of clinical epidemiology;VOL.67(5),PP.527-372014.

[10] H.K. Mekonen, J.P. Hikspoors, G .Mommen, S.E. Köhler, W.H. Lamers,Development of the ventral body wall in the human embryo. Journal of anatomy;VOL.227(5),PP.673-85,2015.

[11] Y.W. Novitsky, H.L. Elliott, S.B. Orenstein, M.J. Rosen,Transversus abdominis muscle release: a novel approach to posterior component separation during complex abdominal wall reconstruction. The American journal of surgery;VOL.204(5),PP.70916,2012 .

[12] S.B. Orenstein, E.R. Saberski, D.L. Kreutzer, Y.W. Novitsky, Comparative analysis of histopathologic effects of synthetic meshes based on material, weight, and pore size in mice. Journal of Surgical Research;VOL.176(2),PP.423-9,2012.

[13] H.H. El-Mrakby, R.H. Milner,The vascular anatomy of the lower anterior abdominal wall: a microdissection study on the deep inferior epigastric vessels and the perforator branches. Plastic and reconstructive surgery;VOL.109(2),PP.539-43,2002.

[14] M. Tam, A. Hart, S .Williams, R. Holland, D .Heylings, S.Leinster, Evaluation of a computer program ('disect') to consolidate anatomy knowledge: A randomised-controlled trial. Medical teacher;VOL.32(3),PP. 138-42,2010.

[15] E .Saberski, S. Orenstein, Y.Novitsky ,Anisotropic evaluation of synthetic surgical meshes. Hernia;VOL.15(1),PP.47-52,2011.

[16] N .Heptonstall, T. Ali, K.Mankad, Integrating radiology and anatomy teaching in medical education in the UK - the evidence, current trends, and future scope. Academic Radiology;VOL.23(4),PP.521-6,2016.

[17] S. Ali Mirjalili, S.L. McFadden, T. Buckenham, M.D. Stringer, A reappraisal of adult abdominal surface anatomy. Clinical Anatomy;25(7):844502012.

[18] J. Jacob, L .Paul, W. Hedges, P. Hutchison, E. Cameron, D .Matthews, Undergraduate radiology teaching in a UK medical school: a systematic evaluation of current practice. Clinical Radiology;VOL.71(5),PP.476-83,2016.

[19] A.W. Phillips, S.G. Smith, C.F. Ross, C.M. Straus, Improved understanding of human anatomy through self-guided radiological anatomy modules. Academic Radiology;VOL.19(7),PP.902-7,2012.

[20] V.M. Spitzer, A.L. Scherzinger,Virtual anatomy: An anatomist's playground. Clinical Anatomy: The Official Journal of the American Association of Clinical Anatomists and the British Association of Clinical Anatomists;VOL.19(3),PP.192-203,2006.

[21] D .Light, N. Kundu, R .Djohan, C. Quintini, N Gandhi, B.R. Gastman, Total abdominal wall transplantation: an anatomical study and classification system. Plastic and Reconstructive Surgery;VOL.139(6),PP.1466-73,2017.

[22] K.A. Desai, S.A. Razavi, A.M. Hart, P.W. Thompson, A .Losken, The effect of BMI on outcomes following complex abdominal wall reconstructions. Annals of Plastic Surgery;VOL.76,PP. 295-7,2016.

[23] U .Dietz, F. Muysoms, C. Germer, A. Wiegering, Technical principles of incisional hernia surgery. Der Chirurg; Zeitschrift fur Alle Gebiete der Operativen Medizen;VOL.87(4),PP.355-65,2016.

[24] S.O. Sozer, F.J. Agullo, A.A. Santillan, C.Wolf, Decision making in abdominoplasty. Aesthetic plastic surgery;VOL.31(2),PP.117-27,2007.

[25] A. Matarasso, D.M. Matarasso, E.J. Matarasso,Abdominoplasty: classic principles and technique. Clinics in plastic surgery;VOL.41(4),PP.655-72,2014.

[26] O.R. Saldanha, S.F. Azevedo, P.S. Delboni, O.R. Saldanha Filho, C.B. Saldanha, L.H. Uribe, Lipoabdominoplasty: the Saldanha technique. Clinics in plastic surgery;VOL.37(3),PP.46981,2010.

[27] M.L. García-García, J.G. Martín-Lorenzo, A .Campillo-Soto, J.A. Torralba-Martínez, R. LironRuiz, J .Miguel-Perello, Complications and level of satisfaction after dermolipectomy and abdominoplasty post-bariatric surgery. Cirugía Española (English Edition);VOL.92(4),PP.25460,2014

[28] G.O. Collaborators, Health effects of overweight and obesity in 195 countries over 25 years. New England Journal of Medicine;VOL.377(1),PP.1327,2017 . 
[29] G.M. Beer, H.Wallner, Prevention of seroma after abdominoplasty. Aesthetic surgery journal;VOL.30(3),PP.414-7,2010.

[30] T. Friedman, D. Coon, A .Kanbour-Shakir, V. Joseph Michaels, J.P .Rubin, Defining the lymphatic system of the anterior abdominal wall: an anatomical study. Plastic and reconstructive surgery;VOL.135(4),PP.1027-32,2015.

[31] R. Iribarren-Moreno, J .Cuenca-Pardo, G.RamosGallardo, Is plastic surgery combined with obstetrical procedures safe? Aesthetic plastic surgery;VOL.43(5),PP.1396-9,2019.

[32] P.G. di Summa, D.F. Kalbermatten, Abdominoplasty complications and seroma: from prevention to effective treatment. Aesthetic Plastic Surgery of the Abdomen: Springer;VOL.5(3),PP. 487-91,2016.

[33] E.Swanson, Seroma prevention in abdominoplasty: eliminating the cause. Aesthetic surgery journal;VOL.36(1),PP. 23-,2016.

[34] J .Sansoni, G .Hawthorne, G .Fleming, E. Owen, N.Marosszeky, Technical manual and instructions: revised incontinence and patient satisfaction tools. New South Wales, Australia: Centre for Health Service Development, University of Wollongong;VOL.25(21),PP.12-24,2011.

[35] A .Matarasso, R.W. Swift, M. Rankin, Abdominoplasty and abdominal contour surgery: a national plastic surgery survey. Plastic and reconstructive surgery;VOL.117(6),PP.1797$808,2006$.

[36] J .Kim, T.R. Stevenson, Abdominoplasty, liposuction of the flanks, and obesity: analyzing risk factors for seroma formation. Plastic and reconstructive surgery;VOL.117(3),PP.773-9,2006.

[37] J.B. Heller, E. Teng, B.I. Knoll, J. Persing,Outcome analysis of combined lipoabdominoplasty versus conventional abdominoplasty. Plastic and reconstructive surgery;VOL.121(5),PP.1821-9,2008.

[38] A. Costa-Ferreira, M. Rebelo, L.O. Vásconez, J.Amarante, Scarpa fascia preservation during abdominoplasty: a prospective study. Plastic and reconstructive surgery;VOL.125(4),PP.1232-9,2010.

[39] A .Costa-Ferreira, M. Rebelo, L .Vásconez, J.Amarante, Scarpa fascia preservation during abdominoplasty. Aesthetic plastic surgery of the abdomen: Springer;VOL.6(4),PP. 59-73,2016.

[40] J.A .Friedland, T.R. Maffi,MOC-PS (SM) CME Article: Abdominoplasty. Plastic and Reconstructive Surgery;VOL.121(4),PP.1-11,2008.

[41] M. Koller, T.Hintringer, Scarpa fascia or rectus fascia in abdominoplasty flap elevation: a prospective clinical trial. Aesthetic plastic surgery;VOL.36(2), PP.241-3,2012. 